\title{
Characterising seabird vessel interactions associated with demersal ocean trawling: vessel attendance by birds depends on intrinsic and extrinsic predictors
}

\author{
Thomas C. Barnes ${ }^{1,2, *}$, Steven G. Candy ${ }^{3}$, Daniel D. Johnson ${ }^{1}$ \\ ${ }^{1}$ Port Stephens Fisheries Institute, New South Wales Department of Primary Industries, Locked Bag 1, Nelson Bay, \\ NSW 2315, Australia \\ ${ }^{2}$ Institute of Marine and Antarctic Studies, University of Tasmania, Hobart, Tasmania 7001, Australia \\ ${ }^{3}$ Scandy Statistical Modelling Pty Ltd, 70 Burwood Drive, Blackmans Bay, Tasmania 7052, Australia
}

\begin{abstract}
Seabirds are declining on a global scale, and this trend is concerning as they play an important role in the marine ecosystem. The decline is due to multiple reasons, but harvest fisheries are a major contributor. The impact of fisheries, however, appears to vary; demersal trawlers cause mortality of many birds in some areas and very few in others. Fishery-dependent monitoring is required to understand this impact on seabirds, and particularly to better understand the variable impact of demersal trawling. We employed a targeted observer program to gather data on seabird assemblages, catastrophic interactions with trawl vessels and predictors of vessel attendance by the seabirds. The latter is a useful proxy for catastrophic interactions and provides information on potential mitigation. Throughout the program period, 104992 seabirds from $\sim 21$ species attended New South Wales (NSW) ocean demersal trawlers. These species included 7 species of petrel and albatross listed by the IUCN, including the flesh footed shearwater Ardenna carneipes and wandering albatross Diomedea exulans. Two catastrophic interactions were recorded, and intrinsic and extrinsic predictors of vessel attendance (e.g. offal discharge and wind, respectively) were characterised. The results of the study will provide information to managers, with the goal of ensuring the sustainability of NSW ocean trawling -in particular its coexistence with threatened seabirds. The NSW Ocean Trawl fishery appears to directly harm very few seabirds which is not always the case when considering worldwide trawl fisheries. Predictors of attendance such as space, time and offal discharge can potentially be used to mitigate the attractiveness of trawlers to seabirds.
\end{abstract}

KEY WORDS: Albatross $\cdot$ Petrels $\cdot$ Generalised additive mixed models $\cdot$ Zero inflated $\cdot$ Trawling

\section{INTRODUCTION}

The harmful effects of various anthropogenic activities have combined to make seabirds one of the most threatened groups of birds (Croxall et al. 2012, Dias et al. 2019). This trend is concerning as they play important ecosystem roles in nutrient cycling between the marine environment and their breeding areas (Oro \& Martínez-Abraín 2005). In addition, seabirds

\footnotetext{
${ }^{*}$ Corresponding author: tom.barnes@dpi.nsw.gov.au
}

consume biomass of a similar magnitude to global fishery landings (Cury et al. 2011), and breeding failures have been used to indicate collapsed fish stocks (see Piatt et al. 2007); hence, they are regarded as useful indicators of marine ecosystem health (Furness 2003).

Ecological relationships between seabirds and fisheries are complex (Ganassin \& Gibbs 2005, GonzálezZevallos \& Yorio 2006, Wickliffe \& Jodice 2010). For

() The authors 2021. Open Access under Creative Commons by Attribution Licence. Use, distribution and reproduction are unrestricted. Authors and original publication must be credited. 
example, fisheries supply an additional food source for the birds, mainly in the form of bait, discarded bycatch and offal discharge (Garthe et al. 1996). The relationship can be more mutualistic when seabirds and harvesters lead each other to fish (Furness 2003), although any benefits to birds are likely to be short term. In some fisheries, seabirds are often killed as a direct result of fishing (Baker et al. 2007). Fisheriesrelated mortality of seabirds mainly affects the Procellariiformes, including albatrosses (Diomedeidae) and petrels (Procellaridae). These birds are longlived, have a low annual reproductive output and mature late (Warham 1990, Baker et al. 2002, Arnold et al. 2006). Their large body size means that strikes with trawlers and gear are usually harmful (Sullivan et al. 2006); hence, many seabird species are threatened (Croxall et al. 2012, Gallo-Cajiao 2014, Dias et al. 2019) due to the combined effects of life history traits and incidental mortality. Fisheries-related mortality is likely to be the most severe threat to petrels and albatrosses (Phillips et al. 2016). However, in many regions direct deaths and more cryptic ecological effects of fisheries on seabird populations remain unexplored. Studies are needed to determine the numbers and community structure of seabirds attending fishery vessels, as this information forms baselines for monitoring and indicates the risk of mortality or catastrophic interaction (Pierre et al. 2012) and other ecological risks (e.g. Furness 2003).

As there are a variety of fishery 'interactions' that affect seabirds, it is important to define them. In this study, we were concerned with 2 interaction types. The most negative interaction is physical injury and death, herein 'catastrophic interaction' (e.g. collisions with fishing gear, entanglement). The second is vessel attendance or simply 'attendance'. The fact that seabirds are attending vessels means that ecological effects on populations are likely (e.g. abundance of individuals is artificially inflated due to additional food sources) (Furness 2003).

Some components of the seabird-fisheries relationship apply to demersal trawl fisheries. Catastrophic interactions occur as result of warp strikes ( $80 \%$ of mortalities in Croxall 2008) or collisions with netsonde cables (Baker et al. 2002). Some demersal trawl fisheries have reportedly caused the mortality of $\sim 110$ black-browed albatross Thalassarche melanophris per month (González-Zevallos \& Yorio 2006, Sullivan et al. 2006); these studies also report on the mortality of other petrels and albatrosses. Another relationship component between seabirds and trawl fisheries is the provision of an artificial food source for seabirds, provided by the fishers during net hauling, offal discharging and bycatch discarding operations. This component is the primary cause of seabird attendance, potentially leading to catastrophic interactions. In Europe and North America, the operation of nearshore trawl fisheries also strongly influences the distribution, abundance and population trends of seabirds in the regions (Walter \& Becker 1997, Wickliffe \& Jodice 2010). Therefore, when trawl fisheries and seabird spatial ranges overlap there is a possibility of effects on seabird populations.

While several studies have examined the catastrophic and attendance interactions between trawlers and seabirds (Weimerskirch et al. 2000, Wienecke \& Robertson 2002, González-Zevallos \& Yorio 2006, Sullivan et al. 2006, Adasme et al. 2019), there are only 3 such studies off the coast of south-east Australia, only one of which involved trawl fishing. Koopman et al. (2018) studied the effects of demersal trawling on seabirds, Trebilco et al. (2010) examined the impact of pelagic longlines and Norman (2000) conducted a semiquantitative survey of nearshore commercial fishers. Similarly, the impact of penaeid (shrimp or prawn) trawling on seabirds has so far not been studied in Australian waters, and only in a few locations globally (e.g. Walter \& Becker 1997, Wickliffe \& Jodice 2010, González-Zevallos et al. 2011). Therefore, there is a need to characterise catastrophic interactions and demersal trawler attendance by seabirds to understand the influence of trawl fisheries on their populations in south-eastern and eastern Australia, especially due to a recent reduction in numbers of some species in this region (Gorta et al. 2019) and the low latitude of this fishery compared to other trawl fisheries that are known to interact with many birds. Since interactions between seabirds and trawl operations are often cryptic (Gallo-Cajiao 2014), they can potentially have far-reaching effects, including significant mortality (Bartle 1991). Hence, the potentially fatal nature of interactions requires targeted approaches to gather quantitative evidence and enable analysis.

The lack of quantification of the effects of fisheries on seabirds has been earmarked as a major concern by international, Australian national and state agencies. For example, in 2009 the FAO expanded its International Plan of Action for Reducing Incidental Catch of Seabirds in Longline Fisheries (IPOASeabirds) (FAO 1999) to cover catastrophic interactions between seabirds and all types of fishing gear used by industrial, recreational and customary fishers. In response, Australia developed and implemented the National Plan of Action for Minimising 
Incidental Catch of Seabirds in Australian Capture Fisheries (Department of Agriculture and Water Resources 2018). The New South Wales (NSW) government recently implemented a new approach to managing the marine estate (ocean, estuaries and coastal wetlands) (NSW DPI 2017b) that identified threats and risks to the estate from fishing and other activities. The impact of fisheries, including ocean trawling, on threatened, endangered and protected species is recognised as a key knowledge gap (NSW DPI 2016). Several studies have suggested that empirical investigations into catastrophic interactions between the Ocean Trawl Fishery (OTF) and seabirds (particularly albatrosses) are urgently needed in NSW (Gallo-Cajiao 2014, Phillips et al. 2016), and that independent monitoring of catastrophic seabird-fishery interactions (including demersal trawling) is required and best facilitated by targeted seabird observers (e.g. Norman 2000). Monitoring can also increase our understanding of long-term population effects.

The NSW OTF is a combination of fish and penaeid trawling. Operations commenced in the 1920s and 1940s, respectively, and peaked in production ( 26000 t) and fleet size ( 430 vessels) in the 1980s (NSW DPI 2004). Both fish and penaeid fisheries use otter trawl gear (a large net held open by 2 large 'doors' and dragged behind the vessel) to catch a variety of taxa, but with different configurations (Graham et al. 2009, Macbeth et al. 2012). In the fish sector, all trawling occurs during the day whilst penaeid trawling is done at night; depths fished range from 25-600 and 30-200 $\mathrm{m}$ for the fish and penaeid fisheries, respectively (Graham et al. 2009, Macbeth et al. 2012). The fishery is managed by input controls, such as limited entry, spatiotemporal closures, boat capacity and gear restrictions (NSW DPI 2017a). Also, output controls regulate the size and limits of the catch (NSW DPI 2017a). Legislative changes came into effect in 2015. A key change was the addition of enhanced protection for aquatic habitats and threatened species provisions.

To assess the impact of the OTF on seabirds, our objectives were to (1a) describe the seabird species and abundance near OTF trawlers and (1b) record the number of seabirds being killed (i.e. catastrophic interactions) as a direct result of trawling in the OTF; and (2) characterise internal (herein intrinsic) and external (herein extrinsic) predictors of seabird vessel-attendance in a component of the OTF (i.e. the OTF South in southern NSW, herein OTFS), as this is a zone adjacent to other fisheries where seabirds are killed. To achieve this objective, we tested the null hypothesis that there is no effect of intrinsic and extrinsic drivers on seabird count numbers for 3 key seabird families (petrels, gulls and albatrosses).

We predicted that the null hypothesis would be rejected; that a combination of intrinsic and extrinsic predictors influence attendance, and therefore catastrophic interactions, based on the attractiveness of trawlers to seabirds and strong spatial effects due to petrels and albatrosses being migratory. The results of the study were assessed in light of potential mitigation options with the overall objective of minimising the impacts of the OTF on seabirds.

\section{MATERIALS AND METHODS}

\subsection{Study region}

The demersal OTF operates off the NSW state coast on the east coast of Australia (see Fig. 1). For our study, we considered 3 sub-fisheries of the OTF: (1) OTFS, (2) Northern Fish Trawl Zone 5 (OTF Central, herein OTFC) and (3) Ocean Prawn Trawl (OTF North, herein OTFN). In general, these fisheries are separated latitudinally, with OTFS operating in the south, OTFC in the middle and the OTFN central-to-north (some small areas overlap; see Fig. 1). Most of the OTFS is restricted to 3 nautical miles (nmi) east or offshore, whilst the other 2 sub-fisheries occupy a greater area and work farther offshore (4000 $\mathrm{m}$ isobath, $70 \mathrm{nmi}$ offshore). Here, the entire OTF was analysed in Objective 1. However, we modelled attendance (Objective 2) only for the OTFS. This was also because of some key fishery differences between the sectors such as night vs. day trawling.

\subsection{Data sources}

Observers recorded seabird attendance and catastrophic interactions in designated seabird observation sessions on randomly selected fishing trips. For OTFS and OTFC trawling operations, these occurred during setting and hauling of the same set and lasted $5 \mathrm{~min}$. Since the OTFN trawled at night, observations were made at dawn and dusk for $30 \mathrm{~min}$, and hence were done on different sets. Observers concurrently counted the number of seabirds attending (details below) and the number of catastrophic interactions. For each catastrophic interaction, observers recorded species, time, vessel net activity, fate and contact points (warps, trawl doors, net, etc.). 
In each designated session during setting and hauling, observers counted and attempted to identify seabirds to species level, although at times only family level identification was possible (cf. Weimerskirch et al. 2000). Seabird numbers needed to be estimated in $\sim 40 \%$ of observer sessions due to the presence of many birds (cf. Weimerskirch et al. 2000). Seabird counts were made in an area defined by a $180^{\circ}$ arc centred on the selected observation position, extending $250 \mathrm{~m}$ astern and $250 \mathrm{~m}$ to each side of the vessel. Other variables were also recorded and formed the intrinsic and extrinsic driver (predictor) variables. For the attendance modelling of the OTFS component, intrinsic variables included net activity (net set and net haul, herein activity), offal discharge (releasing organismal components as a result of cleaning the catch and categorised as yes or no, herein discharge), discarded catch (organisms [in kg] not retained for sale and released overboard, herein discard). Extrinsic variables included latitude, season (austral autumn, winter, spring and summer), year (calendar) and wind (Beaufort wind force scale). Variables were included if they could be classified as intrinsic and extrinsic to ascertain if vessel attendance was mainly due to trawler fishing operations or due to seasonality or weather conditions (etc.), as these variables would be managed differently (e.g. vessel offal management plans versus spatial and temporal closures). Other variables were recorded but are not reported due to collinearity or other reasons. For example, voluntarily deployed mitigation devices such as warp deflectors (Pinkie Buoys), designed to limit catastrophic interactions, were explored but not analysed due to negligible use during observer sessions $(<25 \%)$.

\subsection{Data analysis}

Seabird species, attendance (abundance) and catastrophic interaction data (Objective 1) was qualitatively analysed using text, tables and graphs. Qualitative analysis was carried out on all 3 components of the OTF (OTFS, OTFC and OTFN). Attendance modelling (Objective 2) was undertaken on 3 key seabird families (petrels, gulls and albatrosses) separately, and only included the OTFS data. All attendance data was explored prior to modelling in a manner described by Zuur et al. (2010). Briefly, predictor data was checked for influential data points via Cleveland dot plots, collinearity via pairwise scatterplots with Pearson correlation coefficients and boxplots and interactions via coplots. The response variable was first explored graphically for zero inflation (ZI) and tested statistically using the score test (van den Broek 1995, Yang et al. 2010). Hence, for the OTFS, ZI generalised additive mixed models (GAMMs) were implemented for attendance responses to trawler intrinsic (discards, activity and discharge) and extrinsic (latitude, season, year and wind) predictor variables at the family level. The response variable was attendance (counts) of seabirds, and all observer count data was included (accurate, estimated or extrapolated). GAMMs were appropriate for modelling attendance data with potential for autocorrelation and influence by spatial and temporal predictor variables (Wood 2017). Unique voyage identifiers were included as a random effect in all models, facilitating within-voyage correlation between counts to be controlled (see Nakagawa \& Schielzeth 2010). For example, voyages tended to target specific trawl grounds where certain seabirds may be more or less common than in other grounds that were not targeted. All models were fitted via Poisson and ZI Hurdle family, and log and complementary log-log link to accommodate the count nature of the response data (e.g. Poisson and ZI distributions) and effects of zero counts on the model mean (Wood et al. 2016). Certain predictors were fitted to the ZI part of the model. For example, net activity was explored due to the attractiveness of hauling nets vs. the lack of attraction of setting a clean net likely explaining a substantial portion of the zeros. The final choice of ZI predictor was based on the literature (Sullivan et al. 2006, Brooks et al. preprint: doi:10.1101/132753), data exploration and preliminary model runs. Categorical terms in saturated models were reduced until all remaining covariates were significant at $\mathrm{p}<$ 0.05. For smoothed continuous terms we used the select function (Wood 2017) and began with the form:

Petrel count $=\mathrm{s}($ Latitude: Season $)+\mathrm{s}($ Discards $)+$ Season + Activity + Wind + Year + random (Voyage) $\sim$ Discharge

Gull count $=\mathrm{s}($ Latitude $)+\mathrm{s}($ Discards $)+$ Season + Dis charge + Wind + Year + random (Voyage) $\sim$ Activity

Albatross count $=\mathrm{s}($ Latitude $)+\mathrm{s}($ Discards $)+$ Season + Discharge + Activity + Wind + Year + random (Voyage) Intercept

where the count response variable is shown on the left of the equation and predictors are to the right of the ' $=$ ', ' $s$ ' denotes smoothing spline and predictors separated by ':' indicates an interaction, predictors to the right of ' $\sim$ ' denotes the ZI component of the model.

Continuous fixed effects were fitted with cubic smoothing splines with basis dimension normally set to 4 for each spline term. Diagnostics plots were checked to ensure conformity with assumptions for 
generalised models (Wood 2017, Adasme et al. 2019). All data analysis and visualisation were performed in $\mathrm{R}$ version 3.6.0 (R Core Team 2019), with the 'mgcv' package used for mixed models (Wood 2015).

\section{RESULTS}

\subsection{General}

In total, 498 fishing trips facilitated seabird observations; 76, 68 and 354 in the OTFS, OTFC and OTFN, respectively, representing $\sim 10,10$ and $5 \%$ of the total fishery, respectively. There were 1597 seabird observer sessions $(687,278$ and 632 in the OTFS, OTFC and OTFN, respectively) commonly equating to 2 observer sessions per net shot (one set and one haul) (Table 1). Observations were recorded over multiple years (OTFS and OTFC: 2012, 2014-2016; OTFN: 2017-2019). During observed trips, a total of $261013 \mathrm{~kg}$ of catches were retained $(141830,56692$ and 62491 OTFS, OTFC and OTFN, respectively), and $298751 \mathrm{~kg}$ were discarded (113 477, 44479 and 140795 OTFS, OTFC and OTFN, respectively).

\subsection{Objective 1 -Seabird abundance, species and catastrophic interactions}

\subsubsection{Objective 1 -Seabird abundance and species in the OTF}

In total, 104992 seabirds were observed to attend OTF trawlers $(40553,23834$ and 40605 from the OTFS, OTFC and OTFN, respectively) (Table 1); overall seabird attendances observed varied spatially (Fig. 1) and temporally (Fig. 2). Some seabird families

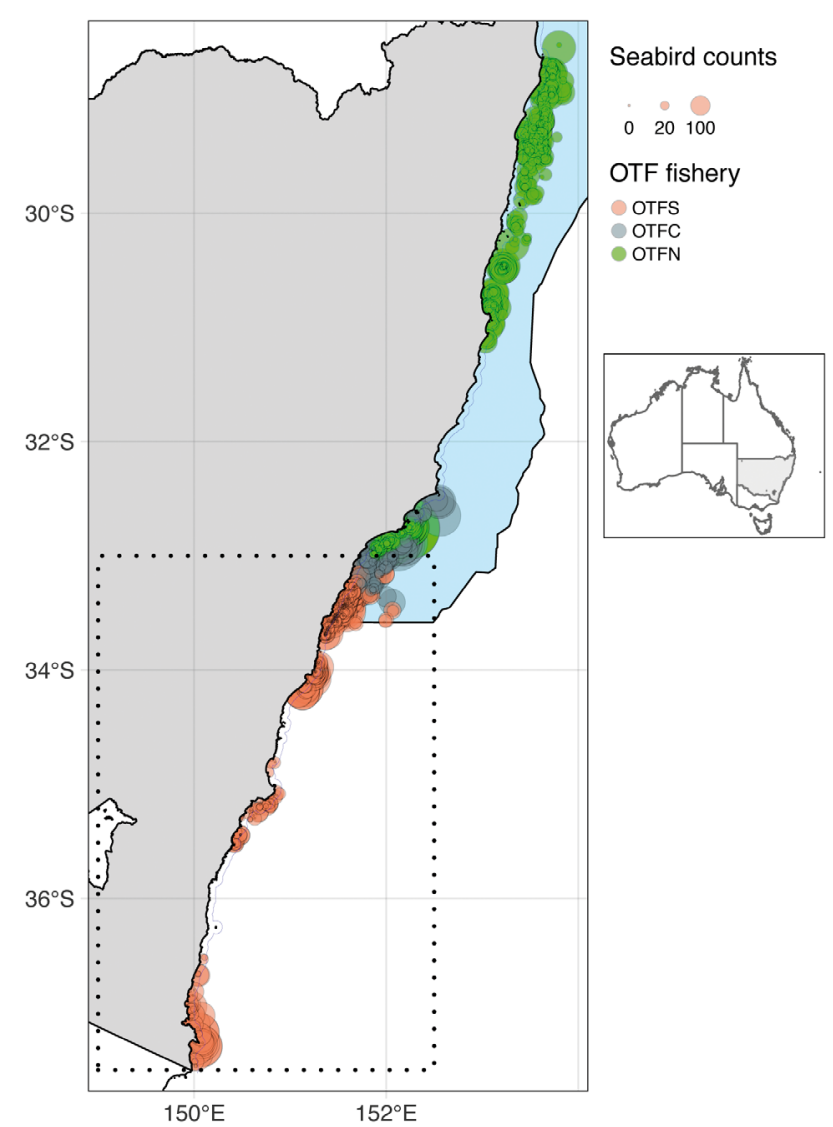

Fig. 1. Study area, with New South Wales (NSW) shaded grey (main and inset map) and seabird abundance (circles) for each observation session over the entire NSW Ocean Trawl Fishery (OTF). Circle colours depict sub-fisheries within the OTF. OTFS: OTF South (fish); OTFC: OTF Central (fish); OTFN: OTF North (penaeid). The entire OTF (including all 3 sub-fisheries) was analysed in Objective 1. Black dotted rectangle: extent of the OTFS, which is the only sub-fishery to have seabird attendance modelling (Objective 2). Thin blue line parallel to coast: 3 nautical mile boundary; light blue shading: $4000 \mathrm{~m}$ isobath, which creates the eastern or offshore boundary for the OTF

Table 1. Mean and frequency of occurrence of seabird observations with counts for the 3 spatial zones of the demersal NSW Ocean Trawl Fishery. (OTFS: OTF South; OTFC: OTF Central; OTFN: OTF North) n: number of observer sessions at the vessel activity level (i.e. each net shot normally includes a set and haul observation equating to 2 sessions). NA = not applicable

\begin{tabular}{|c|c|c|c|c|c|c|c|c|c|c|c|c|}
\hline \multirow{2}{*}{ Family } & \multirow[b]{2}{*}{ Mean } & \multicolumn{2}{|c|}{ OTFS $(\mathrm{n}=687)$} & \multirow[b]{2}{*}{ Count } & \multirow[b]{2}{*}{ Mean } & \multicolumn{2}{|c|}{ OTFC $(n=278)$} & \multirow[b]{2}{*}{ Count } & \multirow[b]{2}{*}{ Mean } & \multicolumn{2}{|c|}{ OTFN (n = 632) } & \multirow[b]{2}{*}{ Count } \\
\hline & & $\mathrm{SD}$ & $\%$ Freq & & & $\mathrm{SD}$ & $\%$ Freq & & & $\mathrm{SD}$ & $\%$ Freq & \\
\hline No seabirds & $224^{\mathrm{a}}$ & NA & 32.61 & NA & $19^{\mathrm{a}}$ & NA & 6.36 & NA & 48 & NA & 7.59 & NA \\
\hline Petrels & 38.22 & 52.91 & 5.56 & 27647 & 31.83 & 30 & 11.45 & 17688 & 61 & 82.42 & 9.65 & 18766 \\
\hline Gulls & 49.8 & 41.72 & 7.25 & 5453 & 73 & 37.77 & 26.26 & 4222 & 163.75 & 184.26 & 25.91 & 21685 \\
\hline Albatross & 43.67 & 49.16 & 6.36 & 7224 & 24.17 & 33.34 & 8.69 & 1790 & 6.33 & 8.39 & 1 & 104 \\
\hline Gannets & 11 & 5.66 & 1.6 & 229 & 6.5 & 0.71 & 2.34 & 36 & NA & NA & NA & NA \\
\hline Pelicans & NA & NA & NA & NA & 7 & NA & 2.52 & 84 & NA & NA & NA & NA \\
\hline Cormorants & NA & NA & NA & NA & 1.67 & 1.15 & 0.6 & 14 & NA & NA & NA & NA \\
\hline Skuas & NA & NA & NA & NA & NA & NA & NA & NA & 1 & NA & 0.16 & 50 \\
\hline${ }^{\mathrm{a}}$ Total counts & & & & & & & & & & & & \\
\hline
\end{tabular}


and species attending vessels overlapped in the 3 study zones (Fig. 2, Table S1 in the Supplement at www.int-res.com/articles/suppl/n044p327_supp.pdf). In the OTFS, flesh-footed shearwaters Ardenna carneipes were most numerous by an order of magnitude (Table S1). In contrast, in the OTFC and OTFN, shorttailed shearwaters A. tenuirostris (Fig. 2) and silver gulls Larus novaehollandiae were the most numerous species, respectively (Table S1). However, undifferentiated shearwaters were more numerous than silver gulls in the OTFN.

In the OTFS, the greatest proportion of observations ( $33 \%)$ were null observations (no seabirds present). In comparison, gulls comprised the largest proportion of observations in both the OTFC and OTFN ( 26\% each; Table 1). The populations of 5 observed species are decreasing in NSW, and 6 are listed by the IUCN as Vulnerable, Near Threatened or Endangered (Table S1). Many of the observed populations do not breed in NSW but are protected by state agency legislation when in NSW coastal waters.

\subsubsection{Objective $1 \mathrm{~b}$ - Seabird catastrophic interactions in the OTF}

Two possible catastrophic interactions between fishing gear and seabirds were observed in the OTFS. One short-tailed shearwater A. tenuirostris was found dead in the trawl net, and one shy albatross Thalassarche cauta collided with a bridle (component of the warp) and died. No catastrophic interactions were observed during wildlife observation sessions $(\mathrm{n}=910)$ in the OTFC and OTFN, which were north of $33^{\circ} \mathrm{S}$ latitude.

\subsection{Objective 2 - Predictors of seabird vessel-attendance in the OTF}

Data exploration identified collinearity between retained and discarded, and vessel velocity and net activity. In addition, the exploration identified spatial and temporal interactions between latitude and season for petrels. Initially, the petrel and albatross ZI GAMMs did not converge, and further exploration showed extreme variation in winter and $\sim 34-33^{\circ} \mathrm{S}$ latitude counts (more details below). The extreme variation may be due to more offshore fishing occurring at this latitude (see Fig. 1) and time of year.

In a significant amount of observation sessions, none of the seabird families were counted $(\sim 50,60$ and $80 \%$ zeros for petrels, gulls and albatrosses,

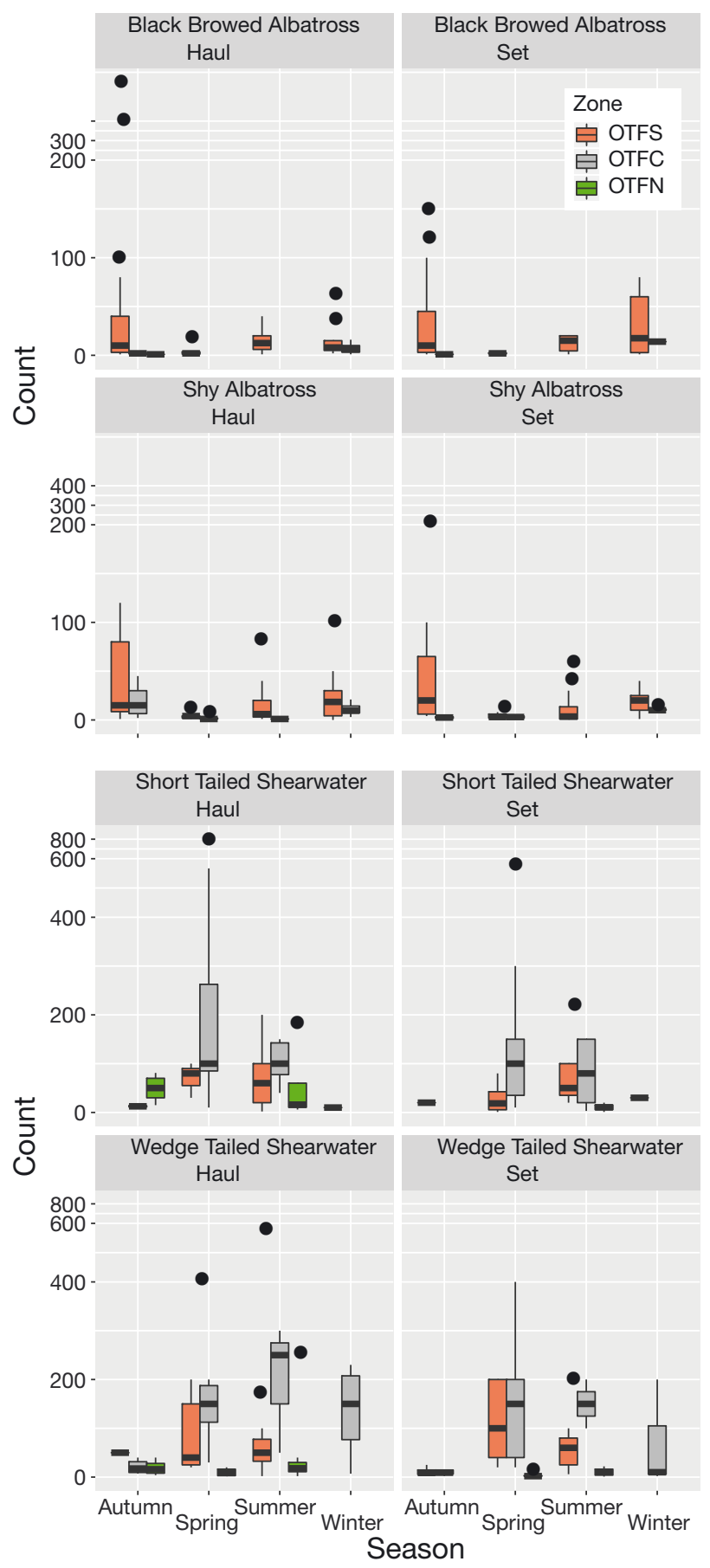

Fig. 2. Boxplots with median and interquartile range of vessel attendance of key seabird species by season and vessel activity (net operations). Whiskers indicate the highest and lowest observations with outliers shown as dots. Upper and lower plots depict attendance by albatross and petrel species, respectively. The $y$-axis scale is squashed in the upper part due to the large ranges with no data. See Fig. 1 for zone abbreviations

respectively). All 3 response variables at the family level returned a significant scores test, indicating a requirement to consider ZI in modelling. 
ZI GAMMs satisfied statistical assumptions via diagnostic plots, although gulls displayed some slight structuring (see QQ plots in Fig. S1 in the Supplement). To obtain the optimal model fit, latitude was modelled as an interaction for petrels but not for gulls and albatrosses (Fig. 3). Normally, the number of knots for smooth terms was set to 4 (for ease of interpretation), but 5 knots greatly improved the model fit for albatrosses. The predictor variable discharge significantly explained the ZI component of the petrel model, whereas it was activity for gulls, and intercept only for albatrosses (Table 2).
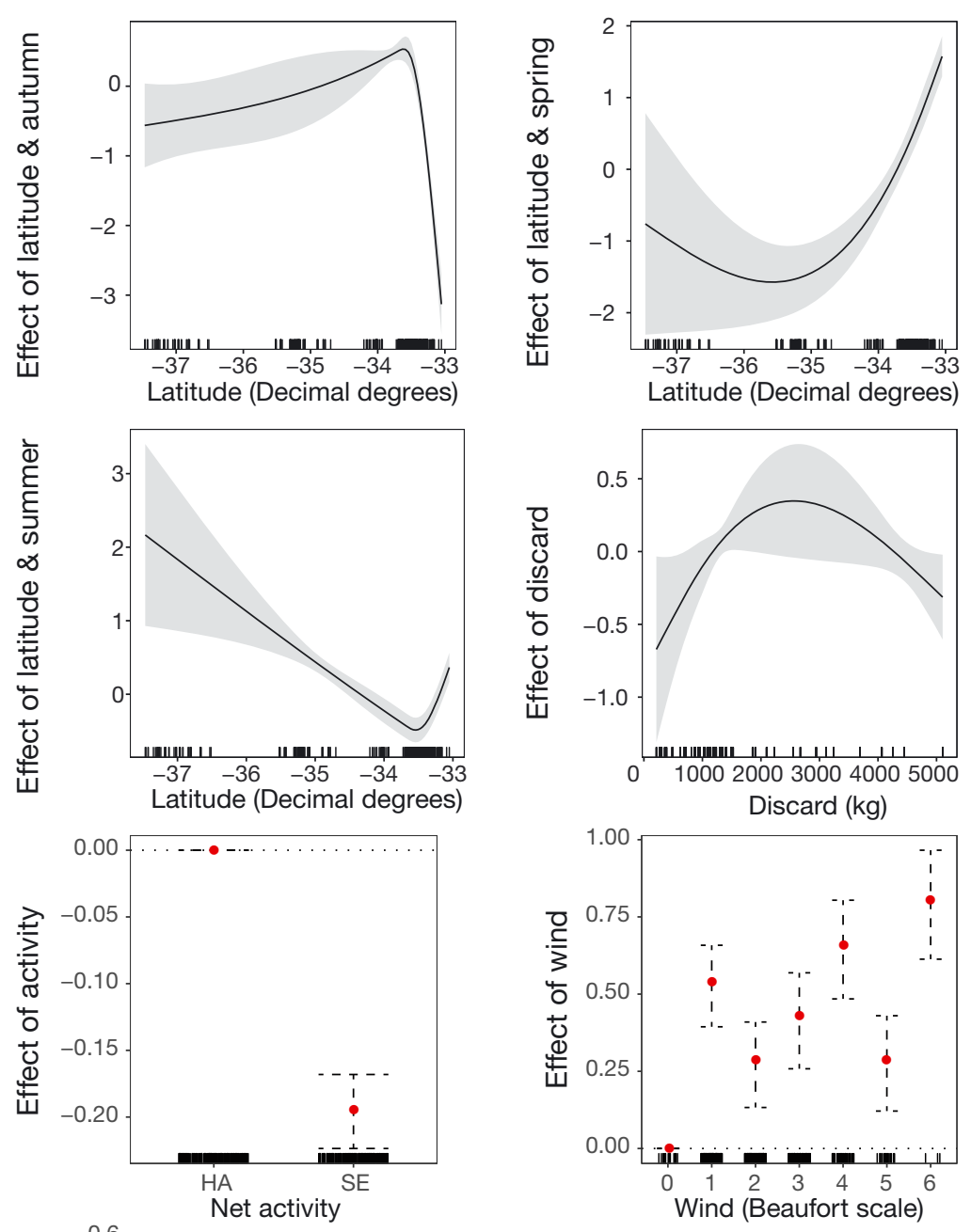

Fig. 3. Upper: effect of significant smoothing function on the attendance rate of petrels. Gray shading: $95 \%$ confidence bounds. Lower: effect of significant factors on petrel attendance rate. Dashed bars: 95\% confidence bounds; dotted line: reference zero effect; rugplots: observation units (upper and lower). HA and

SE: net haul and set, respectively

\subsubsection{Intrinsic predictors}

For the 3 bird families, attendance at vessels was significantly and positively influenced by net hauling (Figs. 3, 4 \& 5), although the effect varied and was not as strong for albatrosses (Figs. 2 \& 5). Offal discharge and bycatch discarding significantly and positively influenced vessel attendance for petrels but not gulls and albatross (Figs. 3-5). However, the influence of discarding was only positive to mid-range discarding quantities (e.g. 900 kg).

\subsubsection{Extrinsic predictors}

Attendance at vessels for the 3 bird families we tested was significantly influenced by latitude. The spatial influence of petrel vessel-attendance interacted with season. The spatial influence within the OTFS extent generally increased with latitude but was lower in autumn and spring, whereas the opposite was the case in summer. Due to extremely large variation in petrel attendance in winter, it was necessary to remove this season from the analysis to facilitate model convergence. Gulls were predicted to attend in greater numbers at mid latitudes in the OTFS (Fig. 4). Albatross attendance significantly decreased with lower latitudes in the OTFS (Fig. 5). In the OTFS, there was extreme variation in albatross attendance at $<34^{\circ} \mathrm{S}$, which was removed to facilitate model convergence.

The ZI GAMMS did not identify a significant influence of season for vessel attendance of albatrosses. However, visual analysis of representative species (to aid in interpretation of family-level patterns), suggests a stronger attendance by these 2 albatrosses in autumn followed by winter in the OTFS (Fig. 2). 
Table 2. Configuration of Poisson and zero inflated (ZI) generalised additive mixed models with log-log link function used to characterise predictors of seabird vessel-attendance. All models included voyage as a random effect. Asterisks indicate significance: ${ }^{* * *} \mathrm{p}<0.001 ;{ }^{* *} \mathrm{p}<0.01 ;{ }^{*} \mathrm{p}<0.05$ for continuous predictor variables; for categorical variables (factors), significance varied at the factor level for some predictors

\begin{tabular}{|c|c|c|c|c|}
\hline Model & Poisson variables & ZI variable & Smooth df & $\begin{array}{c}\text { Deviance } \\
\text { explained (\%) }\end{array}$ \\
\hline Petrels & $\begin{array}{l}\text { Latitude and season }{ }^{* *}+\text { Discard }^{* *} \\
+ \text { Activity }^{*}+\text { Wind }^{*}\end{array}$ & Discharge & $\begin{array}{c}\text { Latitude and season } 2.40-2.90 \text {, } \\
\text { Discard } 0.98\end{array}$ & 63.8 \\
\hline Gulls & Latitude $^{* * *}+$ Activity $^{*}+$ Wind $^{*}$ & Activity & Latitude 1.90 & 47.1 \\
\hline Albatross & Latitude $^{* * *}+$ Activity $^{*}+$ Wind $^{*}$ & Intercept & Latitude 4.92 & 91.8 \\
\hline
\end{tabular}
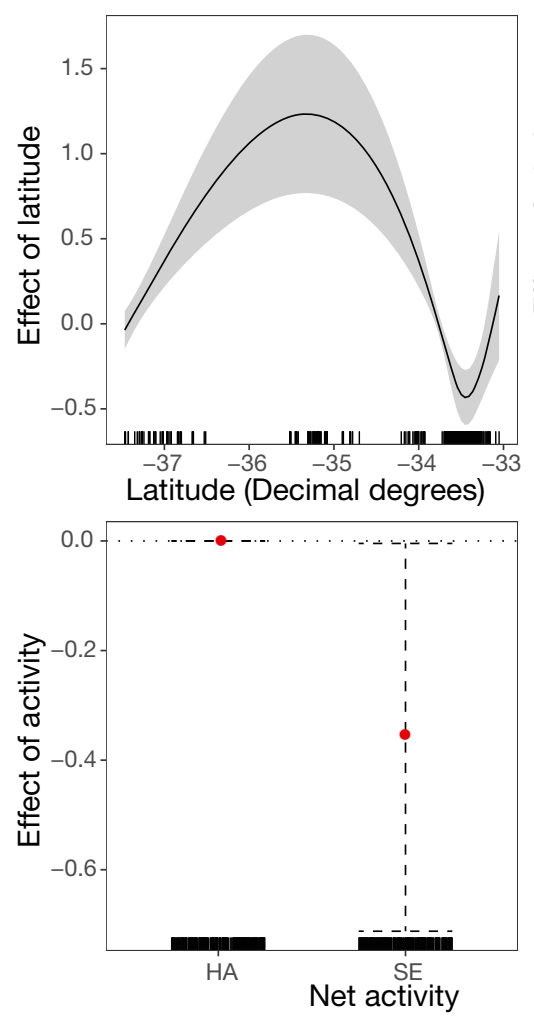

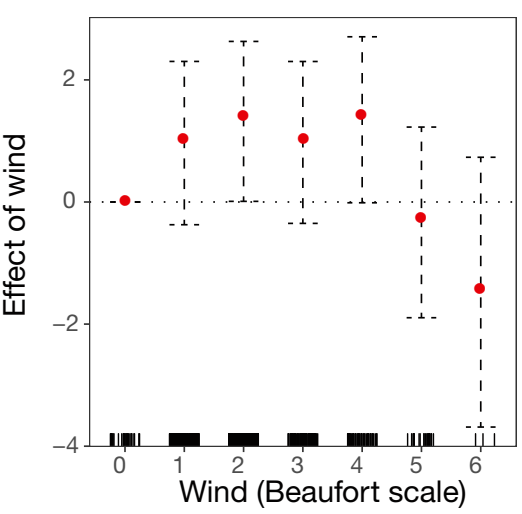

Fig. 4. Effect of significant smoothing function (top left) on the attendance rate of gulls. Gray shading: $95 \%$ confidence bounds. Effect of significant factors on gull attendance rate (top right and bottom). Dashed bars: 95\% confidence bounds; dotted line: the reference zero effect. Rugplots: observation units (both plots). HA and SE: net haul and set respectively

\section{DISCUSSION}

By characterising seabird and OTF interactions, we have addressed an important knowledge gap suggested by the literature (Gallo-Cajiao 2014, Phillips et al. 2016) and broader obligations from national and international legislation. This study contributes to the growing body of information on the global impact of demersal trawl fisheries on seabirds - the full effects of which are currently unknown. The results of the present study are timely, as seabirds are under threat globally (Dias et al. 2019).

Vessel attendance of our 3 model seabird families was significantly driven by a combination of intrinsic and extrinsic variables in the OTFS component of the OTF. Therefore, we can reject our null hypothesis of no effect, and our prediction of a combination of intrinsic and extrinsic predictors significantly influencing attendance was correct. Petrel and albatross data sets had to be slightly trimmed. The large variation in albatross attendance

Interestingly, the visual analysis suggested the opposite effect for key petrels.

The influence of wind force on vessel attendance was significant in all 3 family models (Figs. 3-5); however, the effect of wind varied. For example, petrels and gulls did not show an easily interpretable pattern. All wind speeds had greater attendance than calm (0) but fluctuated in their influence on petrels (Figs. 3-5), whereas gull attendance was only positively significantly influenced by wind force 2 and 4. Only albatross attendance was significantly negatively influenced (i.e. compared to the reference level 0) at wind force 4 (Fig. 5). (mainly zeros but with a few counts to $\sim 100$ ) occurred between 34 and $33^{\circ} \mathrm{S}$ latitude. This part of the fishery allows more offshore trawling and, as albatross abundance can be greater offshore (see Trebilco et al. 2010), it created some erratic trends in the counts that could not be modelled with the remaining latitudinal extent, which was all contained by the $3 \mathrm{nmi}$ boundary. Whist there was no such effect on the other seabird models, petrels required that winter was removed due to only zero observations in winter (likely due to petrels being strongly influenced by seasonal abundance and some petrels being summer-associated; Gorta et al. 2019). 

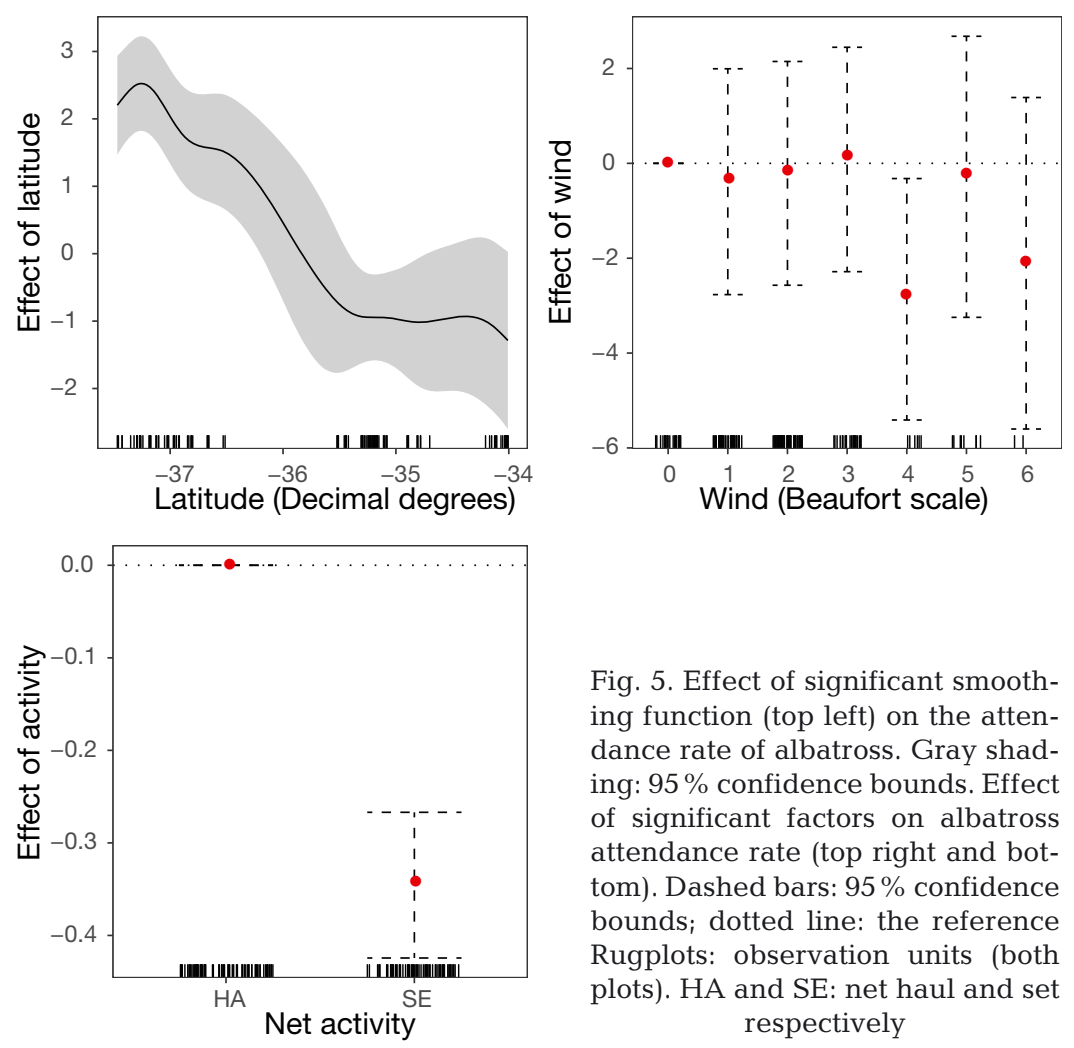

Fig. 5. Effect of significant smoothing function (top left) on the attendance rate of albatross. Gray shading: $95 \%$ confidence bounds. Effect of significant factors on albatross attendance rate (top right and bottom). Dashed bars: $95 \%$ confidence bounds; dotted line: the reference Rugplots: observation units (both plots). HA and SE: net haul and set respectively

ety of items, some of which may not be a desirable shape, type or size (Furness et al. 2007). In the OTF, discharged offal only constitutes a small proportion of likely desirable items. Previous research has provided discharge management strategies, such as timed rather than random discharging and maceration (e.g. Pierre et al. 2012), but these may create issues in small-vessel fisheries like the OTF due to lack of deck capacity. Evolving fish markets, emphasis on greater utilisation of the catch and uptake of bycatch reduction devices should result in less discarding and discharging in trawl fisheries. Greater retention or more selective capture of organisms should benefit seabirds in the long term by reducing catastrophic and attendance interactions, but there could be short-term consequences (see Furness 2003); therefore, a slow and monitored transition is preferred.

As predicted, all seabird models

As predicted, all 3 family group models were positively influenced by net hauling, although the effect size varied between species groups, which has been observed previously (Sullivan et al. 2006). The significant result was expected, as seabirds are attracted to the vessels since they anticipate a provision of food as the net surfaces and is lifted onboard (Sullivan et al. 2006). Seabirds, and particularly petrels and albatrosses, have highly developed senses of sight, smell and hearing (Oro \& Martínez-Abraín 2005) - perhaps particularly acute due to their pelagic lifestyle (i.e. necessity to see fish). Albatrosses have been reported to gather behind trawlers upon activation of the net haul-back winches (Petyt 1995), and this is likely an evolved response (e.g. auditory). Interestingly, sound and other cues have been explored as seabird-fisheries-interaction deterrents with mixed success (see Friesen et al. 2017), but may provide solutions with further research.

Only petrel attendance was significantly and positively influenced by offal being discharged from the vessel. Presence of discharged offal was expected to be very attractive to seabirds as it provides a food source. However, it proved to be a mixed result here, as in other studies (e.g. Weimerskirch et al. 2000). Discharge may not be always attractive to seabirds because it can contain a variwere significantly influenced by latitude. For albatrosses, the predicted attendance followed their expected spatial distribution (i.e. more birds in the south and less in the north). Petrels followed an opposite trend; however, this depended on the season, which was likely driven by the most abundant species (flesh footed shearwater). Vessel attendance for this species has been found to be positively influenced by warmer than average sea surface temperatures (Gorta et al. 2019); in the operational area of the OTF, sea temperatures were generally warmer in the lower latitudes. Petrels and albatrosses breed in discrete colonies, with the albatross breeding sites at much lower latitudes (Weimerskirch et al. 2000). However, some petrels breed offshore from the OTF in summer and further south in SE Australia, leaving this area for the Northern Hemisphere in winter (Hindwood \& D'Ombrain 1960), thus explaining the dominance of petrel species in our data. As albatrosses are just foraging in the OTF and NSW more broadly, their abundance is reduced compared to higher latitudes, especially during the summer breeding season (B. Baker pers. comm.). Interestingly, gulls were predicted to mainly attend OTFS vessels at mid latitudes, possibly because of their avoidance of the larger bodied or more aggressive birds, particularly albatrosses. Reinforcing the latitudinal pre- 
dictions is the observed petrel and albatross attendance in the unmodelled, lower latitudes of the OTF (Table S1, Fig. 2). Importantly, the latitudinal predictions followed the expected trends despite some spatial gaps in sampling and a slightly uneven proportion of observation sessions.

The effect of season was a significant predictor of petrel attendance as a main effect but not for albatrosses and gulls. Some albatross species breed biannually; thus, their foraging in the OTFS may not be seasonally consistent. However, graphical analysis of representative species (see Fig. 2) suggests albatrosses may be more abundant in the austral autumn and winter whereas petrel numbers may increase during spring and summer. Another study supported the seasonal trends although there was variation amongst some petrels (but not short tailed or wedge tailed shearwaters Puffinus pacificus; Brandis et al. 1992). Importantly, precision of seasonal trends may be lost due to models using a family-level response variable, suggesting the need for new technology and training to improve identification of birds to species level.

The description of seasonal predictors of seabird attendance provides important information for designing potential mitigation responses to interactions, and for designing future surveys (particularly for petrels and albatross). For example, if petrel mortalities increase or negative behavioural impacts of attending trawlers are determined, the seasonal attendance results could potentially inform management (e.g. seasonal closures). Hypothetically, the latitude and seasonal interaction suggests that a spatial temporal closure or special trawling rules could be implemented during spring between 34 and $33^{\circ} \mathrm{S}$, and between 37 and $34^{\circ} \mathrm{S}$ in summer. Albatrosses are likely mainly attending trawlers in autumn and winter whilst on non-breeding season foraging trips. Therefore, monitoring of this seabird family away from breeding colonies, such as in the OTF, would be best timed during autumn and winter.

Two catastrophic interactions were recorded by observers in the OTF. These occurred in the OTFS, the zone of greatest albatross attendance in the OTF. In the lower-latitude components of the OTF (OTFC and OTFN), zero catastrophic interactions were observed. As the observer program is just a snapshot, fishery-wide extrapolation of the number of birds killed in the OTF is not appropriate. In other fisheries near the OTFS, including demersal trawl (Koopman et al. 2018) and pelagic longline (Trebilco et al. 2011), many more catastrophic interactions were observed. An estimated 18000 catastrophic interactions be- tween seabirds and trawl warp cables were reported to occur annually in a South African fishery (Croxall 2008), whereas only 5 petrels were reported killed by Australian trawlers at higher latitudes over 1000 observation sessions (Baker et al. 2002). Therefore, each demersal trawl fishery should be assessed individually. As seabird abundance, especially that of vulnerable albatrosses, is generally lower in lower latitudes, it may reduce competition; hence, less catastrophic interactions occur as there is less brazen behaviour (see Sullivan et al. 2006). The relationship between attendance and catastrophic interactions has led to attendance being used as a predictor of catastrophic interactions (e.g. Sullivan et al. 2006) due to catastrophic interactions being difficult to model (i.e. often rare events in trawl fisheries; Baker et al. 2002). Petrels and albatrosses are more susceptible to mortality from fisheries than other birds, and it is likely that a combination of behaviour (aggressive) and body size (inertia causes substantial damage during strikes) (Sullivan et al. 2006) coupled with life history traits (biannual breeding) (Baker et al. 2007) negatively affects their populations. Trawl warp strikes are a common form of catastrophic interaction (Baker et al. 2007, Croxall 2008) and caused the death of the black browed albatross in the present study, despite the presence of a mitigation device (Pinkie Buoy). Pinkie Buoys (or warp deflectors) have been found to provide a $75.10 \%$ reduction in heavy albatross warp collisions (Pierre et al. 2014). Another common form of catastrophic interaction is caused by netsonde cables (Baker et al. 2002). However, these were not employed in the OTF. Other studies have suggested netsonde removal may substantially reduce seabird mortality (Wienecke \& Robertson 2002). It is possible that cryptic mortalities occurred in the present study, as they commonly transpire (see Gallo-Cajiao 2014). Also, catastrophic interactions potentially occurred outside the observation session. The present study suggests use of mitigation devices could continue to be voluntary, but in conjunction with a search for new designs and enhanced periodic monitoring, especially with regard to cryptic interactions.

The results of the present study demonstrate that a combination of intrinsic and extrinsic variables explain variations in seabird vessel-attendance. A variety of seabirds, including threatened species, utilise the OTFS (and the entire OTF) at certain times and are attracted close to vessels during certain trawl operations. It is possible that operations could be modified to reduce ecological impact via careful management. However, seabirds may have grown dependent on 
fisheries as an additional food source (Garthe et al. 1996). Therefore, continued monitoring is critically important to assess ecological effects of the OTF on seabirds. The apparent lack of catastrophic interactions in the OTF possibly reduces urgency, but seabirds will benefit from long-term ecosystem-level planning in the OTF. The implementation of harvest strategies by NSW Department of Primary Industries is timely, given that this approach will likely consider ecosystem-level impacts.

Acknowledgements. Funding for this work was provided by the New South Wales Commercial Fishing Trust (Project no. RDE581-1) and the Marine Estate Management Strategy (Project no. PVF19/611). Field sampling was carried out under permit P01/0059(A)-2.0 and Animal Research Authority NSW DPI 07/03. Thanks to Mike Yates, Chris Burns and Timothy Davie of the Australian Fisheries Management Authority (AFMA) for the highly professional provision of observer services throughout the field sampling phase of the program. This project would have not been possible without a dedicated team of scientific observers who provided invaluable technical expertise and committed effort with respect to on board sampling. Dr. Barry Baker provided useful information on the ecology of large bodied seabirds. Dr. Alistair Becker is thanked for useful review and editorial comments. Finally, this project would not have been possible without the assistance of OTF vessel owners, skippers and their crews who voluntarily hosted and assisted observers during observation trips.

\section{LITERATURE CITED}

Adasme LM, Canales CM, Adasme NA (2019) Incidental seabird mortality and discarded catches from trawling off far southern Chile $\left(39-57^{\circ} \mathrm{S}\right)$. ICES J Mar Sci 76 : 848-858

Arnold JM, Brault S, Croxall JP (2006) Albatross populations in peril: a population trajectory for black-browed albatrosses at South Georgia. Ecol Appl 16:419-432

Baker GB, Gales R, Hamilton S, Wilkinson V (2002) Albatrosses and petrels in Australia: a review of their conservation and management. Emu 102:71-97

* Baker GB, Double MC, Gales R, Tuck GN and others (2007) A global assessment of the impact of fisheries-related mortality on shy and white-capped albatrosses: conservation implications. Biol Conserv 137:319-333

Bartle J (1991) Incidental capture of seabirds in the New Zealand subantarctic squid trawl fishery, 1990. Bird Conserv Int 1:351-359

Brandis C, Chafer C, Smith L (1992) Seabirds recorded off Wollongong, New South Wales 1984-1990. Aust Bird Watch 14:165-179

* Croxall J (2008) Seabird mortality and trawl fisheries. Anim Conserv 11:255-256

Croxall JP, Butchart SH, Lascelles B, Stattersfield AJ, Sullivan B, Symes A, Taylor P (2012) Seabird conservation status, threats and priority actions: a global assessment. Bird Conserv Int 22:1-34

Cury PM, Boyd IL, Bonhommeau S, Anker-Nilssen T and others (2011) Global seabird response to forage fish depletion - one-third for the birds. Science 334:1703-1706
Department of Agriculture and Water Resources (2018) National plan of action for minimising incidental catch of seabirds in Australian capture fisheries. DAWR, Canberra

* Dias MP, Martin R, Pearmain EJ, Burfield IJ and others (2019) Threats to seabirds: a global assessment. Biol Conserv 237:525-537

FAO (Food and Agriculture Organization of the United Nations) (1999) International plan of action for reducing incidental catch of seabirds in longline fisheries. www. fao.org/3/X3170E/x3170e02.htm (accessed 15 January 2019)

*Friesen MR, Beggs JR, Gaskett AC (2017) Sensory-based conservation of seabirds: a review of management strategies and animal behaviours that facilitate success. Biol Rev Camb Philos Soc 92:1769-1784

Furness RW (2003) Impacts of fisheries on seabird communities. Sci Mar 67(Suppl 2):33-45

Furness RW, Edwards AE, Oro D (2007) Influence of management practices and of scavenging seabirds on availability of fisheries discards to benthic scavengers. Mar Ecol Prog Ser 350:235-244

Gallo-Cajiao E (2014) Evidence is required to address potential albatross mortality in the New South Wales Ocean Trawl fishery. Pac Conserv Biol 20:328-335

Ganassin C, Gibbs P (2005) Broad-scale interactions between fishing and mammals, reptiles and birds in NSW marine waters. Fisheries Final Report Series No. 80. NSW Department of Primary Industries, Sydney

* Garthe S, Camphuysen K, Furness RW (1996) Amounts of discards by commercial fisheries and their significance as food for seabirds in the North Sea. Mar Ecol Prog Ser 136:1-11

* González-Zevallos D, Yorio P (2006) Seabird use of discards and incidental captures at the Argentine hake trawl fishery in the Golfo San Jorge, Argentina. Mar Ecol Prog Ser 316:175-183

González-Zevallos D, Yorio P, Svagelj WS (2011) Seabird attendance and incidental mortality at shrimp fisheries in Golfo San Jorge, Argentina. Mar Ecol Prog Ser 432: 125-135

Gorta SB, Smith JA, Everett JD, Kingsford RT and others (2019) Pelagic citizen science data reveal declines of seabirds off south-eastern Australia. Biol Conserv 235: 226-235

KGraham KJ, Broadhurst MK, Millar RB (2009) Effects of codend circumference and twine diameter on selection in south-eastern Australian fish trawls. Fish Res 95:341-349

*Hindwood KA, D'Ombrain AF (1960) Breeding of the shorttailed shearwater (Puffinus tenuirostris) and other seabirds on Broughton Island, NSW. Emu 60:147-154

Koopman M, Boag S, Tuck GN, Hudson R, Knuckey I, Alderman R (2018) Industry-based development of effective new seabird mitigation devices in the southern Australian trawl fisheries. Endang Species Res 36:197-211

Macbeth WG, Millar RB, Johnson DD, Gray CA, Keech RS, Collins D (2012) Assessment of relative performance of a square-mesh codend design across multiple vessels in a demersal trawl fishery. Fish Res 134-136:29-41

*Nakagawa S, Schielzeth H (2010) Repeatability for Gaussian and non-Gaussian data: a practical guide for biologists. Biol Rev Camb Philos Soc 85:935-956

Norman F (2000) Preliminary investigation of the bycatch of marine birds and mammals in inshore commercial fisheries, Victoria, Australia. Biol Conserv 92:217-226 
NSW DPI (New South Wales Department of Primary Industries) (2004) Ocean trawl fishery environmental impact statement. NSW Department of Primary Industries, Cronulla

NSW DPI (2016) NSW marine estate threat and risk assessment-background environmental information. NSW Department of Primary Industries, Sydney

NSW DPI (2017a) Assessment of the NSW Ocean Trawl Fishery-prepared for the Department of the Environment and Energy for the purpose of assessment under Part 13 and 13(A) of the Environment Protection and Biodiversity Conservation Act 1999. NSW Department of Primary Industries, Sydney

NSW DPI (2017b) New South Wales marine estate threat and risk assessment report - final report. NSW Department of Primary Industries, Sydney

Oro D, Martínez-Abraín A (2005) Ecology and behavior of seabirds. In: Duarte CM, Lott Helgueras A (eds) Encycolopedia of life support systems. EOLSS/UNESCO, Oxford

Petyt C (1995) Behaviour of seabirds around fishing trawlers in New Zealand subantarctic waters. Notornis 42:99-115

Phillips RA, Gales R, Baker G, Double M and others (2016) The conservation status and priorities for albatrosses and large petrels. Biol Conserv 201:169-183

Piatt JF, Sydeman WJ, Wiese F (2007) Introduction: seabirds as indicators of marine ecosystems. Mar Ecol Prog Ser 352:199-204

Pierre JP, Abraham ER, Richard Y, Cleal J, Middleton DAJ (2012) Controlling trawler waste discharge to reduce seabird mortality. Fish Res 131-133:30-38

Pierre J, Gerner M, Penrose L (2014) Assessing the effectiveness of seabird mitigation devices in the trawl sectors of the southern and eastern scalefish and shark fishery in Australia. Final Report. Australian Fisheries Management Authority, Canberra

R Core Team (2019). R: a language and environment for statistical computing. R Foundation for Statistical Computing, Vienna. https://www.R-project.org/

Editorial responsibility: Rebecca Lewison,

San Diego, California, USA

Reviewed by: 2 anonymous reviewers
Sullivan BJ, Reid TA, Bugoni L (2006) Seabird mortality on factory trawlers in the Falkland Islands and beyond. Biol Conserv 131:495-504

* Trebilco R, Gales R, Lawrence E, Alderman R, Robertson G, Baker GB (2010) Characterizing seabird bycatch in the eastern Australian tuna and billfish pelagic longline fishery in relation to temporal, spatial and biological influences. Aquat Conserv 20:531-542

* van den Broek J (1995) A score test for zero inflation in a Poisson distribution. Biometrics 51:738-743

* Walter U, Becker P (1997) Occurrence and consumption of seabirds scavenging on shrimp trawler discards in the Wadden Sea. ICES J Mar Sci 54:684-694

Warham J (1990) The petrels: their ecology and breeding systems. Academic Press, San Diego, CA

*Weimerskirch H, Capdeville D, Duhamel G (2000) Factors affecting the number and mortality of seabirds attending trawlers and long-liners in the Kerguelen area. Polar Biol 23:236-249

Wickliffe LC, Jodice PG (2010) Seabird attendance at shrimp trawlers in nearshore waters of South Carolina. Mar Ornithol 38:31-39

Wienecke B, Robertson G (2002) Seabird and sealfisheries interactions in the Australian Patagonian toothfish Dissostichus eleginoides trawl fishery. Fish Res 54:253-265

Wood S (2015) Package 'mgcv'. R package version 1:29. https://cran.r-project.org/web/packages/mgcv/index.html

Wood SN (2017) Generalized additive models: an introduction with R. Chapman and Hall/CRC Press, Boca Raton, FL

Whood SN, Pya N, Säfken B (2016) Smoothing parameter and model selection for general smooth models. J Am Stat Assoc 111:1548-1563

Yang Z, Hardin JW, Addy CL (2010) Score tests for zeroinflation in overdispersed count data. Comm Stat Theory Methods 39:2008-2030

* Zuur AF, Ieno EN, Elphick CS (2010) A protocol for data exploration to avoid common statistical problems. Methods Ecol Evol 1:3-14

Submitted: June 22, 2020

Accepted: November 30, 2020

Proofs received from author(s): March 16, 2021 